EDITORIAL

\title{
EDUCAÇÃO E CONSTITUINTE: CARTA DE GOIÂNIA REVISITADA
}

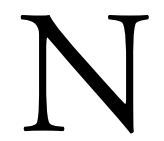

o dia 5 de outubro de 2018, a Constituição Federal brasileira chegou ao seu $30^{\circ}$ aniversário, o mais longo período de vigência de um texto constitucional democrático em nossa história. Educação \& Sociedade, em seus 40 anos de existência, acompanhou de perto todo o processo de redemocratização, a abertura que resultou no texto constitucional de 1988 e os enfrentamentos antes, durante e após o processo constituinte, sempre com o propósito de, por intermédio da difusão e divulgação do conhecimento produzido, amplificar e qualificar o debate sobre os desafios postos à consolidação de um sistema nacional de educação público, igualitário, gratuito, laico e de qualidade social.

O capítulo da Educação na Constituição de 1988 (artigos 205 a 214) deve muito aos persistentes movimentos que atuaram em defesa da escola pública no Brasil. É emblemática desse processo a Carta de Goiânia, resultante da IV Conferência Brasileira de Educação (CBE), realizada sob a temática "Educação e Constituinte", em Goiânia, entre 2 e 5 de setembro de 1986, ou seja, poucos meses antes da abertura do processo da Constituinte. Já no Manifesto de Abertura da IV CBE, foram apresentados os princípios de uma política nacional que mereceriam proteção na Constituição a ser redigida e aprovada. Expressou-se, naquele momento, forte chamamento para que os educadores e as educadoras assumissem sua responsabilidade social no movimento de âmbito nacional, procurando imprimir dimensôes democráticas na concepção de um projeto nacional, expresso na Constituiçáo, conhecido como política educacional da nova República. Foi com esse propósito que se debateram as propostas e se formulou, no fim, a Carta de Goiânia, aprovada na Assembleia Final da Conferência, contendo os 21 princípios da concepção de educação, sociedade e Estado, propostos para serem inscritos no texto constitucional:

\section{CARTA DE GOIÂNIA}

Os participantes da IV Conferência Brasileira de Educação reivindicam, assim, que a nova Carta Constitucional consagre os princípios de direito de todos os cidadãos brasileiros à educação, em todos os graus de ensino e do dever do Estado em promover os meios para garanti-la. Ao mesmo tempo, se comprometem a lutar pela efetivação destes princípios, organizando-se nas suas entidades, exigindo compromissos dos candidatos às Constituintes a nível federal e estadual e cobrando o cumprimento de medidas propostas para a democratização da educação.

DOI: 10.1590/ES0101-73302018v39n145ED 
Propóem que os princípios formulados sejam inscritos no texto constitucional:

1. A educação escolar é um direito de todos os brasileiros e será gratuita e laica nos estabelecimentos públicos, em todos os níveis de ensino.

2. Todos os brasileiros têm direito à educação pública básica comum, gratuita e de igual qualidade, independentemente de sexo, cor, idade, confissão religiosa e filiação política, assim como da classe social ou da riqueza regional, estadual ou local.

3. O ensino fundamental com 8 anos de duração é obrigatório para todos os brasileiros, sendo permitida a matrícula a partir dos 6 anos de idade.

4. O Estado deverá prover os recursos necessários para assegurar as condiçóes objetivas ao cumprimento dessa obrigatoriedade, a ser efetivada com um mínimo de 4 horas por dia, em cinco dias da semana.

5. É obrigação do Estado oferecer vagas em creches e pré-escolas para crianças de 0 (zero) a 6 anos e 11 meses de idade, com caráter prioritariamente pedagógico.

6. São assegurados aos deficientes físicos, mentais e sensoriais serviços de atendimento pelo Estado, a partir de O (zero) anos de idade, em todos os níveis de ensino.

7. É dever do Estado prover o ensino fundamental, público e gratuito, de igual qualidade, para todos os jovens e adultos que foram excluídos da escola ou a ela náo tiveram acesso na idade própria, provendo os recursos necessários ao cumprimento desse dever.

8. O Estado deverá viabilizar soluçóes que compatibilizem escolarização e necessidade de trabalho do menor trabalhador, e, ao mesmo tempo, captar e concentrar recursos orçamentários para a criação de um Fundo de Bolsas de Estudo a serem destinadas às crianças e adolescentes de famílias de baixa renda, matriculados na escola pública.

9. $\mathrm{O}$ ensino de $2^{\circ}$ Grau, com 3 anos de duração, constitui a segunda etapa do ensino básico e é direito de todos.

10. O ensino, em qualquer nível, será obrigatoriamente ministrado em língua portuguesa, sendo assegurado aos indígenas o direito à alfabetização nas línguas materna e portuguesa.

11. Será definida uma carreira nacional do Magistério, abrangendo todos os níveis e que inclua o acesso com o 
provimento de cargos por concurso, salário digno e condições satisfatórias de trabalho, aposentadoria com proventos integrais aos 25 anos de serviço no magistério e direito à sindicalização.

12. As universidades e demais instituiçóes de ensino superior terão funcionamento autônomo e democrático.

13. As universidades públicas devem ser parte integrante do processo de elaboraçáo da política de cultura, ciência e tecnologia do país, e agentes primordiais na execução dessa política que será decidida, por sua vez, no âmbito do Poder Legislativo.

14. A lei regulamentará a responsabilidade dos Estados e Municípios na administração de seus sistemas de ensino e a participação da União para assegurar um padrão básico comum de qualidade dos estabelecimentos educacionais.

15. Os recursos públicos destinados à Educação serão aplicados exclusivamente nos sistemas de ensino criados e mantidos pela União, Estados e Municípios.

16. Será de responsabilidade exclusiva dos setores da Saúde Pública a atenção à saúde da criança em idade escolar.

17. A merenda escolar e qualquer outro programa assistencial a ser desenvolvido nas escolas devem contar com verbas próprias, desvinculadas dos recursos orçamentários para a Educaçáo stricto sensu, porém gerenciadas por órgáos da área educacional. '

18. É permitida a existência de estabelecimentos de ensino privado, desde que atendam às exigências legais e náo necessitem de recursos públicos para sua manutenção.

19. O Estado deverá garantir à sociedade civil o controle da execução da política educacional em todos os níveis (federal, estadual e municipal), através de organismos colegiados, democraticamente constituídos.

20. O Estado assegurará formas democráticas de participação e mecanismos que garantam o cumprimento e o controle social efetivo das suas obrigações referentes à educação pública, gratuita e de boa qualidade em todos os níveis de ensino.

21. Fica mantido o disposto pela Emenda Calmon (EC 24, $\$ 4^{\circ}$ do art. 176 da atual Constituiçáo), assim como pelas Emendas Passos Porto (EC 23) e Irajá Rodrigues (EC 27) e a lei estabelecerá sançóes jurídicas e administrativas no caso do nãocumprimento destes dispositivos. 
Os educadores presentes à IV Conferência Brasileira de Educação consideram indispensável que seja elaborada uma nova lei de diretrizes e bases da educação nacional, a partir dos princípios inscritos na Constituição. Consideram, outrossim, essencial sua participaçáo, através das entidades de representaçáo na área, tanto na elaboração da Constituição, quanto da lei acima referida.

Consideram, ainda, que devem ser mobilizados todos os recursos no sentido de tornar público este posicionamento e de conclamar os candidatos dos diversos partidos à constituinte, para a defesa dos princípios aqui enunciados.

Goiânia, 5 de setembro de 1986 (CARTA DE GOIÂNIA, 1986).

A transcrição desses princípios impóe-se por razóes diversas: essa Carta foi balizadora da organização dos movimentos da educação na Constituinte e influenciou decisivamente a estrutura do texto constitucional. Aqueles princípios inscritos na Constituição acabaram por influenciar, por sua vez, o reordenamento da educação brasileira na nova Lei de Diretrizes e Bases (LDB). O projeto de reorganização do campo da educação em decorrência da IV CBE, por sua vez, desembocará na iniciativa de criação do Fórum Nacional em Defesa da Escola Pública, tanto na Constituinte quanto nos debates que levaram à LDB, sendo precursor dos movimentos e fóruns contemporâneos.

Nas décadas seguintes à sua promulgação em 1988, o texto da Constituição passou por numerosas e profundas alterações. Nesses 30 anos, tivemos ao todo nada menos que 99 Emendas Constitucionais e seis Emendas Constitucionais de Revisão, totalizando 105 alterações no texto original, além de milhares de normas regulamentadoras e de decisóes judiciais que deram o contorno dos direitos fundamentais e do arranjo jurídico-constitucional hoje em vigor.

Muitas dessas alterações tiveram o propósito de reconfigurar a proposta de 1988, que, em boa medida, expressou o anseio de democratizaçáo da sociedade brasileira pela via dos direitos civis, políticos, econômicos, sociais e ambientais. Em alguns casos, o propósito de reconfiguração resultou, na verdade, em desconfiguração. Isso porque o projeto democratizador de 1988 foi quase que imediatamente abalado por reformas constitucionais cujo objetivo foi tornar o texto constitucional palatável a uma nova hegemonia em construção — o neoliberalismo.

É típica desse revés a Emenda Constitucional de Revisão no 1 , de $1^{\text {o }}$ de março de 1994, que institui o Fundo Social de Emergência, precursor da Desvinculação de Receitas da União (DRU), medida que veio descaracterizar o regime constitucional de financiamento dos direitos à seguridade social (previdência, assistência social e saúde) e educação. Essa medida perdura até hoje, tendo sido ampliado o percentual de desvinculação para 30\% e estendido aos orçamentos de Estados, Municípios e Distrito Federal, com a Emenda Consti- 
tucional no 93, de 8 de setembro de 2016, primeira modificação aprovada sob o Governo Temer (PMDB).

Entretanto, não só retrocessos e desconfigurações caracterizaram os embates nesses últimos 30 anos. Nas décadas seguintes, as entidades científicas, sindicais e populares que compunham o Fórum Nacional, tais como Centro de Estudos Educação e Sociedade (CEDES), Confederação Nacional dos Trabalhadores em Educação (CNTE), Associação Nacional de Pós-Graduação e Pesquisa em Educação (Anped) etc., com o reforço fundamental da Campanha Nacional pelo Direito à Educação, criada em 2001, conseguiram reverter, em parte, os retrocessos do período anterior, ampliaram as fontes de financiamento, o escopo de direitos e garantias fundamentais do direito à educação na Constituição, fortaleceram o Plano Nacional de Educação (PNE) e incluíram na Constituição a demanda por um sistema nacional de educação. Algumas dessas emendas tiveram o claro intuito de inserir princípios de educação pública democrática não contemplados no texto original de 1988 .

Os movimentos populares e educacionais originariamente articulados no Fórum Nacional em Defesa da Escola Pública, portanto, em grande medida responsáveis pelas conquistas em matéria de direitos educacionais na Constituição, seguiram atuantes no pós-1988, resistindo e assegurando conquistas, ainda que em contextos adversos. Cada Emenda Constitucional que ampliou o financiamento e o direito à educaçáo, como as no 53 , de 2006, e n $\mathrm{n}^{\circ} 59$, de 2009 , contou com a pressão e a mobilização decisivas desse campo.

Ao mesmo tempo, repetem-se os enfrentamentos históricos que vêm opondo decisivamente os defensores da escola pública, desde o Manifesto dos Pioneiros da Educaçáo Nova, de 1932, aos setores privatistas e religiosos que querem limitar o campo de ação do Estado na educação, bem como o sentido público da escola. Esses setores também influenciaram decisivamente o processo constituinte de 1987-1988, limitando decisivamente o avanço constitucional em temas como a gestão democrática do ensino e impondo novamente os seus interesses sobre a educação escolar. Dois pontos são emblemáticos nesse processo, com efeitos nefastos que se tornam mais evidentes, sobretudo no atual contexto de retrocessos e ameaças às conquistas de 1988: a autorização de repasse de recursos públicos para a iniciativa privada e o ensino religioso nas escolas públicas de ensino fundamental.

Nossa Constituição, por força dos embates de posiçóes inconciliáveis que se expressam em seu texto, é ambígua por definição. Saber da incompletude característica da Constituição de 1988, um projeto imperfeito, conflitivo e inacabado, é reconhecer a necessidade de seguir lutando em defesa das conquistas democráticas do campo educacional e de sua ampliação. É nesse contexto que celebramos a permanência da Constituição de 1988 e a luta de todos os que batalharam pelo reconhecimento do direito fundamental à educação nas últimas décadas. A luta por direitos é uma luta cotidiana. 
Este número de Educação \& Sociedade está sendo lançado no VI Seminário de Educação Brasileira (SEB), com isso, encerramos as comemoraçôes do $40^{\circ}$ aniversário de nossa revista, comemoramos os 30 anos da Constituição e anunciamos nosso propósito de seguir firmes propiciando este espaço de divulgação científica e de reflexão crítica sobre os graves desafios colocados à educaçáo e à sociedade brasileiras.

\author{
Ivany Rodrigues Pino ${ }^{1}$ \\ Luana Costa Almeida ${ }^{2}$ \\ Antonio Álvaro Soares Zuin ${ }^{3}$ \\ Carmen Sylvia Vidigal Moraes ${ }^{4}$ \\ Celso Joáo Ferretti ${ }^{5}$ \\ Pedro Goergen ${ }^{6}$ \\ Salomáo Barros Ximenes ${ }^{7}$ \\ Sandra Maria Zákia Lian Souza ${ }^{8}$ \\ Theresa Adriáa ${ }^{9}$
}

\title{
Referência
}

ANDE; ANPED; CEDES. Carta de Goiânia. In: Educaçâo \& Sociedade, ano VIII, número 25, dezembro de 1986, pp. 5-10.

\footnotetext{
${ }^{1}$ Editora. Universidade Estadual de Campinas - Campinas (SP), Brasil.

${ }^{2}$ Editora Assistente. Universidade do Vale do Sapucaí - Pouso Alegre (MG), Brasil.

${ }^{3}$ Editor Associado. Universidade Federal de São Carlos - São Carlos (SP), Brasil.

${ }^{4}$ Editora Associada. Universidade de São Paulo - São Paulo (SP), Brasil.

${ }^{5}$ Editor Associado. Centro de Estudos Educação e Sociedade, Universidade Estadual de Campinas Campinas (SP), Brasil.

${ }^{6}$ Editor Associado. Universidade Estadual de Campinas - Campinas (SP), Brasil.

${ }^{7}$ Editor Associado. Universidade Federal do ABC - Santo André (SP), Brasil.

${ }^{8}$ Editora Associada. Universidade de São Paulo - São Paulo (SP), Brasil.
} 